\title{
Blockchain Technology Enhances Sustainable Higher Education
}

\author{
Rocsana Bucea-Manea-Țoniş ${ }^{1} \mathbb{D}$, Oliva M. D. Martins ${ }^{2} \mathbb{D}$, Radu Bucea-Manea-Țoniş $^{3} \mathbb{D}$, Cătălin Gheorghiță $^{4}$, \\ Valentin Kuleto $^{5}$, Milena P. Ilić ${ }^{5, *(\mathbb{D})}$ and Violeta-Elena Simion ${ }^{6}$ (D)
}

1 Faculty of Physical Education and Sports, Spiru Haret University, 060057 București, Romania; rocsense39@yahoo.com

2 Campus de Santa Apolónia, Instituto Politécnico de Bragança, 5300-253 Bragança, Portugal; oliva.martins@ipb.pt

3 Faculty of Economic Sciences, Hyperion University, 030615 Bucharest, Romania; radub_m@yahoo.com

4 Department of Manufacturing Engineering/TCM, Faculty of Industrial Engineering and Robotics, 313, Splaiul Independentei University POLITEHNICA of Bucharest, 060042 Bucharest, Romania; catalin.gheorghita@upb.ro

5 LINK Group Belgrade, Faculty of Contemporary Arts Belgrade, Information Technology School ITSBelgrade, University Business Academy in Novi Sad, 11000 Belgrade, Serbia; valentin.kuleto@its.edu.rs

6 Faculty of Veterinary Medicine, Spiru Haret University, 030045 Bucharest, Romania; ushmv_simion.violeta@spiruharet.ro

* Correspondence: milena.ilic@its.edu.rs

\section{check for} updates

Citation: Bucea-Manea-Țoniş, R.; Martins, O.M.D.; Bucea-Manea-T,oniş, R.; Gheorghiță, C.; Kuleto, V.; Ilić, M.P.; Simion, V.-E. Blockchain Technology Enhances Sustainable Higher Education. Sustainability 2021, 13, 12347. https://doi.org/10.3390/ su132212347

Academic Editors: Rocsana Bucea-Manea-Tonis and Gheorghe Orzan

Received: 27 September 2021 Accepted: 5 November 2021 Published: 9 November 2021

Publisher's Note: MDPI stays neutral with regard to jurisdictional claims in published maps and institutional affiliations.

Copyright: (c) 2021 by the authors. Licensee MDPI, Basel, Switzerland. This article is an open access article distributed under the terms and conditions of the Creative Commons Attribution (CC BY) license (https:// creativecommons.org/licenses/by/ $4.0 /)$.
Abstract: This research investigates blockchain technology, focusing on the influence of motivation on collaborative work, which positively influences learning performance in Higher Education Institutions (HEI). In addition, blockchain technology is correlated with decentralisation, security and integrity, and anonymity and encryption. It can also be perceived as a consensus mechanism, rewarding students, professors, and universities as a smart contract. Therefore, this technology has been used to improve higher education. It also allows less informed people to interact with better-informed peers and mentors. Finally, this study aims to enhance the current state of blockchain applications comprehension. The methodology used for this research includes document analysis, literature review, content analysis (blockchain platforms), the case study method, and the survey method. In statistical considerations, aiming to evaluate indicators, this research presents the Composite Reliability Analysis, Cronbach Alpha Coefficients, and the Bootstrapping method (Variance Inflation Factor). All these analyses aimed to present a designed research model. This exploratory research gathered data from 150 students at 3 universities in Serbia, Romania, and Portugal. As demonstrated, using student motivation has a significant and positive impact on the quality of student collaborative work. Student collaborative work also correlates with students' higher level of engagement in the educational process, and the more engaged students are, the better their learning outcomes will be. As a result, in higher education, student involvement boosted learning outcomes. Researchers found that motivation, teamwork, and student involvement were important factors in improving student learning outcomes, as were blockchain-based tools. The results from the quantitative analysis indicate that Collaborative work, Motivation, Engagement, MOOCs, AR, VR, Gamification, and Online class were associated with learning performance.

Keywords: sustainable education (SE); blockchain; massive open online courses (MOOCs); artificial intelligence (AI); e-learning; educational platforms; distributed ledger technology (DLT); higher education (HE); higher education institution (HEI)

\section{Introduction}

The concept of "planetary well-being" is a guiding aspiration that establishes an ideal regulation of both humanity and the planet, including an integrated system of sustainability of natural and social aspects [1]. Nevertheless, sustainable education (SE) in the era of millennials, generation $Z$, and the Alpha generation must be based on the following three 
pillars as the first is already part of the education system and the latter will enter the system more or less at the same time when blockchain technology will become a part of the education system:

- to be equitable, inclusive, and nudge personal development, even though life-long learning approaches, including digital, transversal, and practical skills, i.e., critical thinking, communication, collaboration, information literacy, analytical skills, metacognitive and reflection skills, and other research skills, as a condition to adapt to the continuous challenges of green market context [2];

- developing digital and transversal competences, investing in people to facilitate their employability, creative work, and resilience required by professions;

- developing innovative curricula, new methods, and technologies in teaching and evaluation, such as MOOCs (Massive Open Online Courses), VR (Virtual reality)/AR (augmented reality), blockchain, videoconferences, etc. [3].

The behavioural changes which emerged in the younger generations inescapably led to the reshaping of learning itself. Consequently, teaching methodologies are being updated to keep up with the evolution of learning and, especially, to train future professionals for both labour and professional careers markets. On the other side, the demand for Higher Education (HE) has increased, and new technologies have been seen as an asset to learning. However, learning is a cognitive process and a social one, which involves interaction. Therefore, from a broader perspective, education must be sustainable in time. In this case, Sustainable Education (SE) is a significant concept that promotes employability and involves continuous, inclusive, and equitable learning. A digital transversal may assist practical skills, new methods and technologies in teaching and assessment. Moreover, SE includes all stakeholders-students, professors, universities, communities, etc.

The learning loss is enormous if we account for the context of disruptive forces, continuously shifting geopolitical powers, and, presently, the pandemic that has affected over 1.6 billion learners. Moreover, $86 \%$ of children in low-income countries are effectively out of school due to school closures, compared with only $20 \%$ in high-income countries [4]. Nevertheless, any crisis offers new opportunities for sustainable development education. Advanced technologies, such as AI, Robotics, 5G, machine learning, blockchain, e-learning, educational platforms, virtual classrooms, and others, can offer real support [5].

About 6.7 million learners, children, and young people from 3 to 18 years old were impacted by school closures in Spain [6]. As a result, online information sources gained relevance, and new technologies, e.g., virtual reality (VR) or artificial intelligence (AI), may play an important role [7]. The value creation also can be measured by implementing VR/AR simulation [8]. However, according to the authors, only VR consulting firms with a solid academic background, such as university spin-offs, have combined qualitative data to measure cognitive behaviours that influenced participants' performance [7].

More and more areas are emerging in innovative blockchain approaches. Thus, blockchain technology is used to enhance higher education, and developing an educational infrastructure to support learning is part of the present. Innovative science learning relationships often involve sustained individual inquiry, intense social interaction with interest groups, and expert mentoring relationships [8]. Blockchain technology allows less informed people to interact with better-informed colleagues and mentors [9]. Our study aims to demonstrate that blockchain applications can be implemented in education or industry. Moreover, the proposed case study shows a simple solution for solving and implementing this technology in the academic network. Therefore, the main research issues this study addresses are the significant opportunities for HEIs if implementing blockchain technologies; the significant challenges HEIs face while implementing blockchain technologies (research problem).

Regarding the concept of the paper and its organisation, this is an original research paper for which the IMRAD model was used to present the theoretical and empirical basis of the research. 
The researcher's goal is to describe the current state of blockchain technology in higher education, analyse its benefits and drawbacks, and propose solutions that HEIs can use. In addition, this study investigates How can HEIs benefit from blockchain technology, and while implementing blockchain technologies, what significant issues do HEIs face. Those are the central research questions of this article.

The motivation for the research lies in the fact that we, the authors of this article, have been individually involved in the development processes of implementation of Information technologies in HEI and other processes in our countries for decades. We have initiated the implementation of blockchain technologies in higher educational institutions and EdTech companies we are employed or own.

This study's added value is mainly due to the lack of research into how blockchain technology is used in HEI. In addition, because the use of blockchain technologies in higher education is still nascent in many countries, we believe that the findings of this research will be of great importance for countries of all income levels, but especially those in low and middle-income categories.

Document analysis (literature review) is used in this paper to gather qualitative information and knowledge gains. Using the following model, the document analysis process involved accessing relevant documents, creating an organisational chart, verifying the authenticity of the documents, and discovering the content within each of them. The data was collected from 150 students from 3 universities in Serbia, Romania, and Portugal, representing exploratory research. Their opinions were coded and analysed through composite reliability analysis, Cronbach's Alpha Coefficient, Average Variance Extraction, and bootstrapping at the end that emphasised the opportunities and challenges brought by blockchain implementation in HEI.

\section{Materials and Methods}

The state of the art evaluation, participation observation, and a case study model were used as methodological approaches in the research. Document analysis was also used. In addition, a survey was conducted among college students. We took this approach because we are all university professors, involved in instructional methods, and deal with students daily. Additionally, literature or document analysis is also an excellent way to acquire information in the social sciences. Surveys are a handy tool for obtaining quantitative data and performing quantitative analysis. In digital (online) form, it is a low-cost tool, and, in terms of identifying those who use technological tools efficiently, it is highly valued.

We have kept objectivity and avoided bias in our analysis by conducting it with multiple coders; having participants check our results helped us maintain objectivity. We used various statistical techniques to ensure the correctness of the results. A thorough literature review that uncovered new information aided our fact-checking efforts by helping us verify the findings with additional data sources and helping us explore alternate explanations.

\section{Research and Results}

\subsection{Primary Research (Document Analysis)}

\subsubsection{Teaching Methods}

As in other fields of activity, in education, the classical methods are still intertwined with the new, 21st Century methods, which are beginning to grow in importance as they are implemented. Presently, the pandemic has collapsed businesses and has caused substantial job losses, lost skills, lost productivity, and higher personal and national debts. These economic downfalls increased inequalities, social divisions, and environmental degradation [10]. In education, the unevenness can be mitigated by a meritocracy approach and providing effective systems and technological support for learning, identifying, and fostering students' extraordinary talents. Each school must invest in exceptional skills to bring the most innovations in a future sustainable economy [10].

New technologies, coupled with a pandemic context, presents new and unique challenges for the next generation, including mastering new technology to complete their jobs. 
The new generation must be prepared for these challenges from school. Blockchain proved to be efficient in many activities of the entire life-chain of Higher Education (HE), from student recordkeeping to issuing diplomas and job matching [11,12].

Methods of teaching change through teaching and learning styles, such as inquiry, e.g., asking appropriate questions, project-based, problem-solving, i.e., meet a sustainable goal, innovative solutions (VR/AR, Massive MOOCs, Gamification, videoconferences), active teaching and learning by doing, experimenting, simulating, etc. [11,12]. For example, blockchain can change society and create a new social and financial ecosystem [13]. These methods should be integrated teaching and learning that encourages students to explore, explain a problematic phenomenon, elaborate projects, and solve the problem. The evaluation should be performed as positive feedback and a performance-based assessment. In this approach, the selection of good skills may provide a more personalised classroom-oriented teaching and learning because each student learns differently, i.e., some of them learn by reading, and others learn by memorising or doing, experimenting, listening, etc. [14,15].

According to [16], the gamification design can result in engagement and better learning performance, as presented in Figure 1.

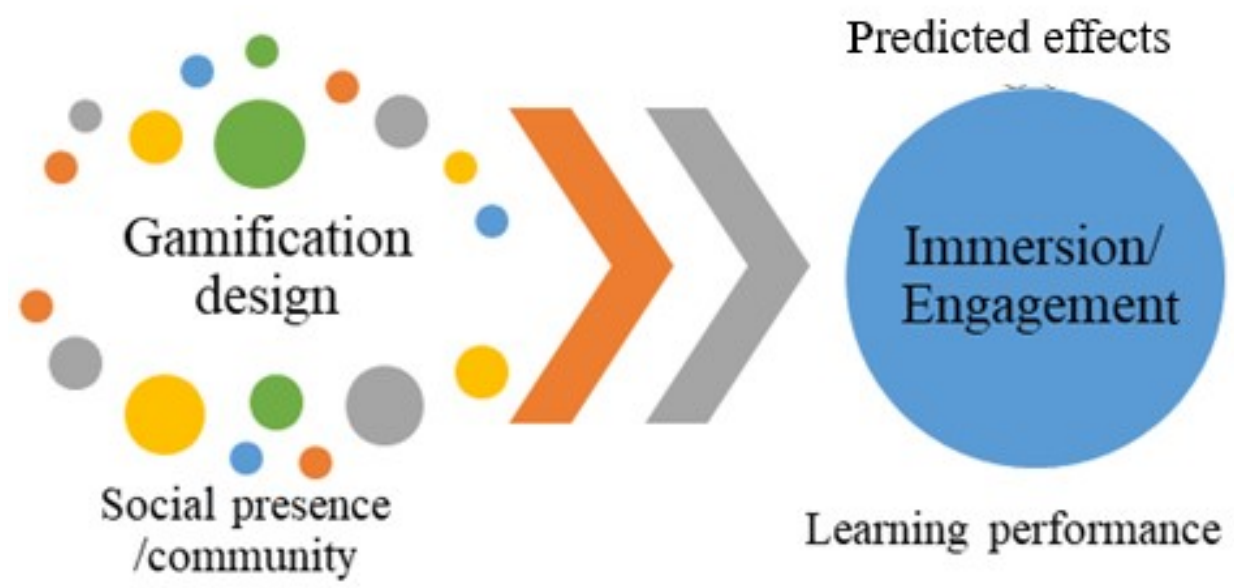

Figure 1. Relating gamification design with the education performance, adaptation after [16].

Each person comes up with solutions to the education problem and learns to have fun in the process, as playing, for example. However, rules must be enforced. With assumed teaching and learning, students can make a significant performance and excellence distinction between their future roles as employees, managers, and visionaries. They will also acquire skills such as creating worlds with their imaginations, imagining things that are not possible, and developing visionary thinking to see something that does not yet exist. It is essential to leverage intelligence to drive growth and reduce risk in strategic choices as well. A sustainable education will be based on ethics, values, and the capacity of students and professors to adapt to the continuously changing and multi-faceted world. It means discovering what students should learn, the ways of teaching, how they can appropriate broader competences, and how education needs to change to achieve the goal [3,17-20]. A way to teach and most straightforward to test is to digitise, automate, and outsource. That value is less and less created vertically through command and control and increasingly horizontally by whom you connect and work with.

\subsubsection{Blockchain Platforms-Advantages and Disadvantages}

Blockchain is similar to a ledger that records digital forms and shares information across a computer network that includes digital signatures and certificates. However, in the context of education, it aids transparency, permanently authenticates, and accesses the learning and performance metrics through complex cryptology algorithms that authenticate the entire system's integrity [21]. For example, the simplest way to describe blockchain technology is a decentralised, distributed ledger that proves a digital asset's ownership. 
Blockchain platforms that have already been tested are Khan Academy, Tutellus, etc. These platforms nudge peer-to-peer learning for students, teachers, and professional communities (business). Offering appropriate competencies for market labour is essential to train the teacher to provide personalised learning experiences for teachers through innovations in curricula, teaching methods, and digital resources.

The disruption of learning and increased use of technology resulted in the emergence of a "hybrid model": School-Based Learning and Home-based learning and increased use of online communication through Zoom, Facebook, Amazon, MOOCs, Google Classroom, and other advanced blockchain platforms based on blockchain technology such as Khan Academy, Tutellus, Sony Global Education (SGE), APPII, SuccessLife, TeachMePlease (TMP), GradBase, ODEM, Blockcerts, Parchment, and Echolink. These platforms have different advantages and disadvantages [3,22], as presented in Figure 2.

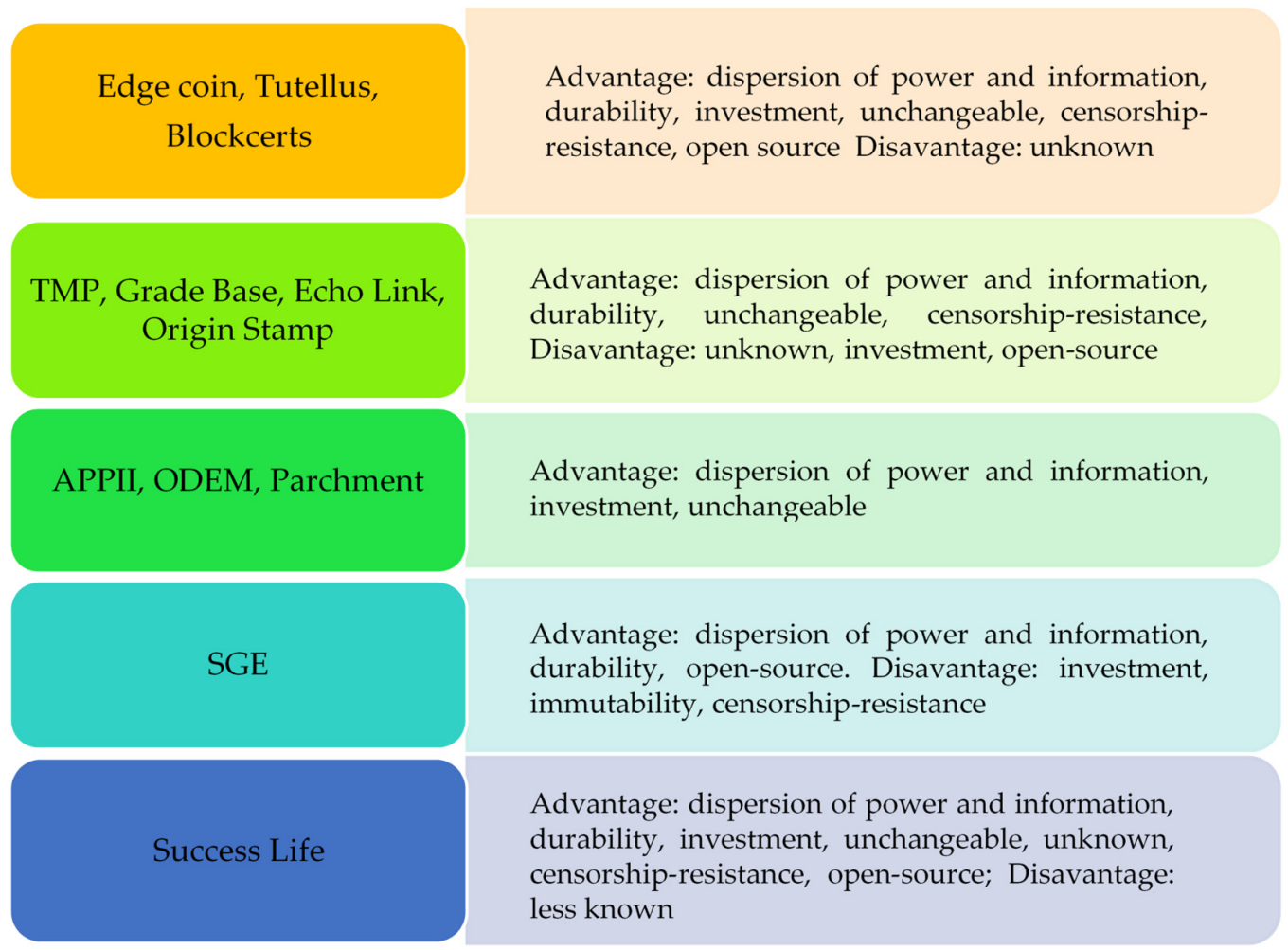

Figure 2. The main advantages and disadvantages of blockchain platforms: adaptation after [22].

Blockchain's facilities [23-27] are decentralisation, traceability, consensus mechanism (agreement data in multiagent frameworks or distributed processes are DPOS, POW, and POS), currency (different algorithms are used in creating a new cryptocurrency, used for payment and accounting), smart contract (blockchain protocol is used in coding secure financial agreements, which many counterparts can activate, and immutability (data entered remain unchanged, being controlled by all the counterparts). Some challenges are associated with applying blockchain when using wireless communication [28]. Blockchain facilities are used in different situations [10,22,29], for example:

- Decentralisation, smart contract, and transaction rate are necessary features in the management of the content library (the students save their work on a device, and after a while, he can continue to improve it on another, as the service is platformindependent), publications, and cooperative learning; using intelligent contracts ensures the transparent conduct of transactions without an intermediary;

- Distributed Cloud data storage provides security and integrity to blockchain transactions;

- Distributed storage and the choice of a recognised validation algorithm protect against Denial of Service (DoS) attacks; 
- Anonymity and encryption are essential when depositing personal data (GDPR);

- Transaction rate, e.g., when students pay taxes, must be followed by an E-Certificate, with a digital signature that can be archived and accessed with public and private keys;

- The smart contract is often used in B2B paradigms and job offers, reducing the unemployment rate by presenting job opportunities to skilled and certified persons. In this case, an integrated scoring and tokenising system are required. Depending on the type of business, we can choose between free-access, restricted blockchains, or even federated blockchains;

- Traceability is used when feedback is essential and in a ledger of students, professors, universities, files, marks, diplomas, courses, etc.; once a transaction is stored, it can no longer become reversible; at most, one can add a block that will cancel the previous transaction if it passes the validation stage;

- Rewarding students, professors, and universities can be accomplished within a consensus mechanism and smart contracts that offer tokens; these tokens can be transformed into virtual currency; using cryptocurrencies dedicated to a blockchain but interchangeable with other cryptocurrencies, the students are conditioned/ allowed to use these tokens or virtual currency in restricted networks libraries or books stores that contain educational literature;

- Consensus Mechanism, Smart Contract, and Currency are used by the Token system.

Blockchain in education is essential for students, universities, and entrepreneurs to establish standardisation and validation of the educational system and its stakeholders to be met to mitigate fraud. Thus, comparisons between degrees obtained in different countries and translation problems can be avoided [30]. In addition, it is crucial to solve security problems on the Internet—such as authentication, storage, and certification-and reduce costs and time with academic research verification, increasing transparency. Certification, e.g., degrees, transcripts, students' competencies, achievements, and professional ability, will be trustable and credible for all companies worldwide [29]. The significant differences between skills validation and certification verification between universities and companies emerge in essential gaps in the workforce. Blockchain comes with solutions for universities and companies to verify, validate, and aggregate individual "learning notes" [31].

The blockchain application is highly dependent on context and evaluating it requires considering whether it is appropriate for a specific application. As long as there is no central authority tracking and storing data, university recordkeeping would work with distributed ledger technology (DLT). Thus, students go from course to course based on their ability, and each student is assessed on their own. It is tough to justify this use case as long as a formal curriculum and learning program with a sequential course sequence exists. However, this example could work if a new school is willing to bankroll MOOC's outcomes delivery from a more comprehensive entity and receive student certification when the student meets requirements. There needs to be cooperation from the establishment in order to adopt this system. When using DLT to store content that protects use and copyright, the use case is entirely different. When examining these consequences, it can be found that they are numerous and complicated.

Blockchain technology keeps a complete record of course in data blocks in sequential order by timestamps. The old and new data blocks cannot be deleted, and the cryptographic algorithm prevents data tampering and reduces fraud [30]. Therefore, this technology is no longer at the beginning of the evolution in the academic environment. However, there is still a lack of an educational infrastructure to support the learning of this technology. The purpose of this case study is to provide a simple way to use Blockchain to present courses: MOOCs, XR, video, simulations, gamification, etc. The purpose was also to reward teachers and students for their activities with tokens that might be transformed into virtual currency to store and access only educational data and research. One priority of UE and most universities is the digitalisation of hybrid higher education and ensuring the formation/education of students with innovative knowledge and transferable competencies and skills for a mindset and a sustainable behaviour change to reach Green Deal objectives $[3,32,33]$. This 
study is a practical approach that shows that motivation influences collaborative work that influences blockchain and learning performance in HEIs.

Blockchain can be applied in the higher education sector for many purposes, such as the following [34]:

Recordkeeping

Student record keeping is a very costly and time-consuming activity that can be performed with minimum effort using blockchain technology [35,36]. Information such as personal details (name, identification, address, etc.), courses attended and marks, and degrees obtained, and diplomas obtained are secured in blockchain platforms and are trust$\mathrm{ful} /$ transparent for all counterparties. Thus, there is no need to verify them every time it is required. They will result in a virtual transcript of all educational achievements throughout one's entire life to prevent CV fraud and facilitate streamlined student transfers between universities [36]. Furthermore, universities may not emit a paper diploma but provide a link where it is available, preventing thefts from using fake degrees for employment. MIT has already implemented blockchain-stored diplomas since 2017. In this regard, our study is a relevant example.

Professors can protect their courses' intellectual property (IP), ideas, inventions, and patents based on blockchain. Thus, the plagiarism problem can be easily combated. The plagiarised research papers will also be discovered very quickly. Professors will reduce the spread of copyright courses on the Internet, saving it in a secure chain with advanced encryption. The data will be accessed by permitted network users [37].

Educational institutions must face high competition since the Internet crashed the space and time limits. In their struggle to enrol and engage, students face the challenges of international and national accreditation. Moreover, the post-COVID-19 context brings new accreditation criteria such as digitalisation, hybridisation, entrepreneurship, social inclusion, green and circular economy, etc. Blockchain can facilitate this complex process of accreditation that will ensure the quality of teaching, learning, practising, and business communication worldwide [29].

Another advantage of digital recordings is matching the skilled, certified student with job offers by companies and matching different organisations' requirements.

File storage Universities can deposit all documents such as curricula, research reports and projects, degrees, etc., in blockchain, ensuring data security and reducing cost with storage space, choosing storage services such as Filecoin [38].

A synthetic representation of the flux of activities, knowledge, courses accessed and controlled by students through their educational data on e-portfolios, feedback, and accreditation is presented in Figure 3.

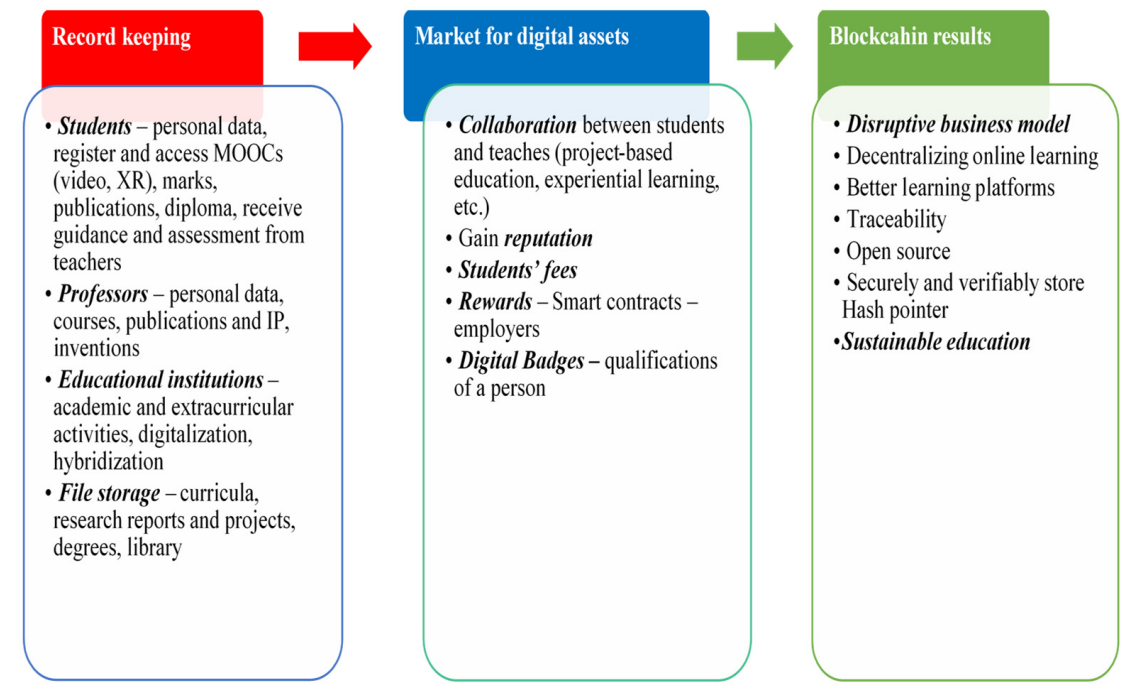

Figure 3. Blockchain in higher education. 
This draft helps develop the basis for a blockchain platform associated with higher education.

Create a New Market for Digital Assets [10,39].

Students' fees could be associated with a labour-intensive activity that implies the transfer between different entities, such as students, parents, scholarship-granting agencies, financial institutions, governments, and educational institutions. Universities, such as King's College in New York City, already use cryptocurrencies.

Rewards: Rewards can be obtained through cryptocurrency mining. For example, the computer node that continuously checks the data integrity saved on a blockchain obtains rewards such as digital tokens or ether. In addition, these currencies can be used to buy other educational goods and services because universities accept tokens as payment in cafeterias, books, or courses.

Digital Badges: The students can obtain badges from experts in different study areas in the parties' approval process. Their confidentiality and integrity are based on hashing algorithms [35]. In addition, open Badge Passport offers services that certify different qualifications of a person, such as being a specialist in IT, speaking German, English, and French, and being an excellent swimmer, too [40].

Publishing fees: Students and professors have an interest in publishing the results of their research in high journals. There were very notable cases of good articles that were rejected for publication, probably for being very innovative, difficult to understand, and because of the fear of being fake, etc., but in the end went on to receive prizes for their authors: e.g., Kary Mullis's 1993 paper on a polymerase chain reaction. This inconvenience might be avoided by using blockchain technology. Blockchain technology can keep all the records regarding issues, papers, authors, fees, etc., with blockchain technology.

Create a Disruptive Business Model

This new model of business create value-added through the following methods [2,29,31,34-36,38]:

- Record control for student admissions formalities through distributed ledger technology implemented in decentralised platforms, under a secure environment;

- Library records and services are tacked by the distributed ledger: the tracking of books and students' preference for each book;

- Enhancing and motivating lifelong learning: BitDegree, OECD.io;

- Strengthening student's assessments and career settlement;

- Certificate and identity management: digital credential, consortium, block certs, open source, etc.;

- Rewarding extracurricular activities with certificates of achievement presenting student contributions to an academic institute;

- Ensuring intellectual property protection and reducing plagiarism through smart contracts that can track paper citation and reword authors [37];

- Automated liability, accountability procedures, and administrative tasks;

- Provide records of transparency: public information is accessible for everyone;

- Ensuring data privacy and security: GDPR compliant;

- Cyberpayments and reduced costs: bitcoins and custom cyber coins;

- Scalability: the slow speed of transaction processing in blockchain may determine bottlenecks when trying to scale the educational process worldwide;

- Digital marketing: helping to identify associated or complementary preferences and facilitate the purchase decision process;

- Innovation: this immature technology is associated with a different powerful mindset that implies the active transparent participation of different counterparties: sustainable universities—competitive digital skilled students; sustainable business—sustainable green economy;

- Market option: although the market shows a lack of trust and knowledge on how to harness the potential of blockchain technology in education, there are already educational entities that have implemented blockchain and smart contracts, such as the borderless Woolf University, established by academics from Oxford and Cambridge. 
Their goal is to set up an Airbnb of degree courses, where the relationship between students and teachers implements this new disrupted model, solving challenging problems for traditional technologies. The teachers are rewarded with tokens that can be transformed into cyber currency and students with credits, badges, certificates, and sometimes tokens that can be used to buy other educational services [40];

- This online system facilitates the relationship between teachers, staff, and senior and junior students because they can access lectures and events from all around the world, nudging good long-term relationships between students and faculty;

- The management of transportation and hostel facilities for students and staff can be easier by setting up carpools, reducing traffic and bottlenecks in cities, offering a secure and convenient drive to students, and mitigating the parents' responsibility.

\section{Decentralising Online Learning}

Nowadays, some students want to pay for different modules or take the best courses from different universities. This situation cannot be solved without international credit points and skills offered by course graduation based on blockchain technology because each university has unique specifications and regulations. There are institutions with prerecorded courses that do offer support and feedback for students. With no real-time data exchange, students may be confused regarding the information received and obligated to pay another service to get in contact with a real teacher. Decentralising Online Learning will ensure the real-time online interaction between teachers and students, and the student may have the opportunity to choose between courses from curricula $[10,38]$.

In this decentralised system, courses are stored in intelligent contract blockchains to be set up to be executed automatically when meeting the established conditions. Thus, each teacher can assess tasks for students that the blockchain's smart contracts can automatically check. Then, the teachers are rewarded with cryptocurrency, tokens, and students can gain badges, credits, and after program completion diploma [40].

\section{Creating Better Learning Platforms}

Platforms, such as SGE, Edgecoin, and Tutellus, might be improved to offer all the available facilities, as presented above. Users can buy internal tokens in these platforms to ask for feedback from standby online tutors, access learning materials, e.g., VR courses, and access other educational services. They might invite friends to subscribe and gain tokens. Professors also gain more tokens when users interact with their content. Blockchain ensures the swift interaction between students, instructors, and developers [38,41].

Analysing best practices (case studies), we have learned that using blockchain, colleges will have more options as the best practice case can show (Technical University of Madrid, Spain). Higher education platforms such as Tutellus, SGE, and Edgecoin will be improved. Incredibility, traceability, and security will drive the widespread adoption of blockchain. As a result, it can be used for everything from student fees to digital badges, file storage, and new online learning models.

As physical distance becomes less important in knowledge sharing and networking, blockchain facilities will be a sustainable solution for higher education [42]. Ullah and colleagues discovered that some schools use blockchain technology for educational purposes, while others manage academic degrees and final grades. It requires a college diploma and grade-based tests.

Online courses include group meetings, presentations, and research skills. Nicosia University is using distributed ledger technology (DLT) to verify MOOC credentials. Sony Global Schooling has decided to use blockchain to create a transparent evaluation framework for providing data storage and management services. MIT also created a distributed ledger-based digital badge for online learning. The Holberton School is the first educational institution to use distributed ledger technology (DLT) to store degrees and educational information. Each record in a distributed ledger has a unique student ID [43]. 
3.1.3. Relationship between Student Motivation, Student Collaborative Work, Student Engagement, Student Learning Performance, and Blockchain

A MOOC is a platform in which a blockchain application should trace any interaction between different types of members. Each student can gain some credit points when they solve a task very well $[16,19]$. Teachers can also obtain some credit points for each good video or VR class uploaded for good teaching and interaction with the students [17]. These credit points can be transformed into virtual currency or discount coupons for educational resources.

In conclusion, the platform may offer free online courses and courses that can be virtually paid for. This system will ensure an intense engagement of the teachers and students within the platform, and it will assure a sustainable educational approach. Furthermore, this approach will help students gain competencies rather than content. It will also help them acquire transferable skills rather than discipline-specific skills, which will engage them in problem-solving and system thinking rather than learning STEAM. In this way, the platform can motivate students and stimulate critical thinking, collaboration, communication, and creativity [11].

Critical thinking can be stimulated when the teacher enters the online classroom and presents a problem, asks a question, or asks for a specific task to be solved by the students with their knowledge and skills. If the students cannot solve the problem, then the teacher can give them some clues. In the end, thinking about solving problems, the teacher redirects the students to a video/experiential class, simulation applications, or a specific game where he explains the whole content to be learned. Here, the teacher will present the lesson. In other words, the teacher can stimulate collaboration by asking students to form small groups and solve a project or a problem. In this way, a teacher can also stimulate collaboration and communication between students and creativity $[11,20]$.

So, the teachers may consider teaching less, experimenting more, simulating more, and playing games to solve complex problems. This approach will help us use experiential teaching and learning (meaning-making many experiments in virtual reality), stimulate interacting teaching, and stimulate challenge-based learning (when the students have to solve a problem with their background). This approach will also stimulate inquiry teaching: asking questions as the students find the answer by themselves.

\subsection{Secondary Research: Experimental Data, Complex Analysis, and Significant Results}

To identify some opportunities and challenges associated with blockchain in HEIs and aiming to understand how blockchain can be used in HEIs, a quantitative and qualitative analysis was developed with students from Serbia, Romania, and Portugal, using SmartPLS 3.0. Software. The literature review emphasised the relevance of motivation [44], collaborative work [31,37], and engagement of students [17], as well as the use of blockchain tools $[38,41]$ to improve learning performance [17].

The research objective was to identify the relevance and influence of student motivation, collaborative work, engagement, and blockchain on student learning performance. Figure 4 shows the structural model of analysis. The first variable, V1, is named "Student Motivation". Through Cronbach's Alpha, we verify if items such as student collaborative work, MOOCs, AR, VR, and gamification influence $V 1$. The second variable, $V 2$, is named "Student Collaborative Work". Through Cronbach's Alpha, we test if $V 2$ is influenced by MOOCs, AR, VR, and gamification. The third variable, V3, is named "Student Engagement". Through Cronbach's Alpha, we test if V3 is influenced by student collaborative work, MOOCs, student motivation, AR, VR, and gamification. The fourth variable, V4, is named "Learning Performance". Through Cronbach's Alpha, we test if V4 is influenced by student collaborative work, student motivation, student engagement, MOOCs, AR, VR, and gamification and online classes. Table 1 presents the variables and respective indicators. The fifth variable, V5, is named "Blockchain". Blockchain is used in HE for a massive audience, and through Cronbach's Alpha, we test if V5 is influenced by MOOCs, AR, VR, gamification, blockchain facilities, and videoconferences. 


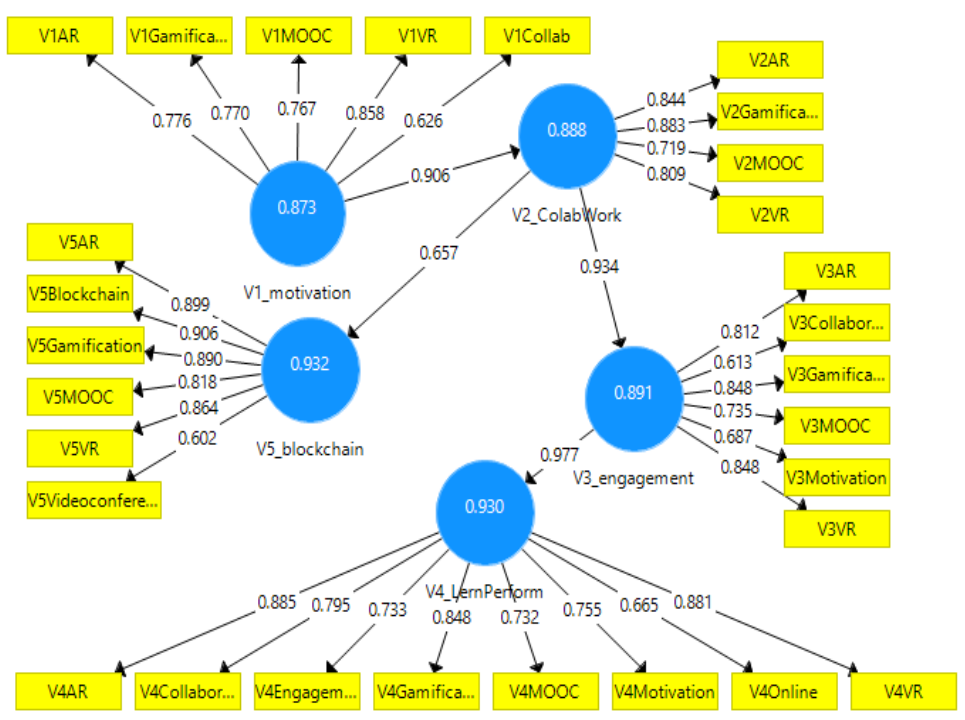

Figure 4. Composite Reliability Model.

Table 1. Variables and their respective indicators.

\begin{tabular}{|c|c|c|}
\hline Variable Name & Code of Indicator & Indicator Name \\
\hline \multirow{5}{*}{ Student Motivation } & V1 Collaborative & V1 Collaborative work promotes student's motivation \\
\hline & V1MOOCs & V1 Massive Online Open Courses (MOOCs) promote student's motivation \\
\hline & V1AR & V1 AR promotes student's motivation \\
\hline & V1VR & V1 VR promotes student's motivation \\
\hline & V1 Gamification & V1 Gamification promotes student's motivation \\
\hline \multirow{4}{*}{ Student Collaborative Work } & V2MOOCs & V2 MOOCs promote students to work collaboratively \\
\hline & V2AR & V2 AR promotes students to work collaboratively \\
\hline & V2VR & V2 VR promotes students to work collaboratively \\
\hline & V2 Gamification & V2 Gamification promotes students to work collaboratively \\
\hline \multirow{6}{*}{ Student Engagement } & V3 Collaborative engagement & V3 Collaborative work promotes student engagement \\
\hline & V3 MOOCs & V3 MOOCs promote student engagement \\
\hline & V3 Motivation & V3 Motivation promotes student engagement \\
\hline & V3 AR & V3 AR promotes student engagement \\
\hline & V3 VR & V3 VR promotes student engagement \\
\hline & V3 Gamification & V3 Gamification promotes student engagement \\
\hline \multirow{8}{*}{$\begin{array}{l}\text { Student Learning } \\
\text { Performance }\end{array}$} & V4 Collaborative & V4 Collaborative work enhances learning performance \\
\hline & V4 Motivation & V4 Motivation enhances learning performance \\
\hline & V4 Engagement & V4 engagement enhances learning performance. \\
\hline & V4 MOOCs & V4 MOOCs enhance learning performance \\
\hline & V4 AR & V4 AR enhances learning performance \\
\hline & V4 VR & V4 VR enhances learning performance \\
\hline & V4 Gamification & V4 Gamification enhances learning performance \\
\hline & V4 Online class & V4 Online classes enhance learning performance \\
\hline \multirow{6}{*}{ Blockchain } & V5 MOOCs & V5 Blockchain is used in HE for a massive audience (MOOCs) \\
\hline & V5 AR & V5 Blockchain is used in HE for a massive audience (AR) \\
\hline & V5 VR & V5 Blockchain is used in HE for a massive audience (VR) \\
\hline & V5 Gamification & V5 Blockchain is used in HE for a massive audience (Gamification) \\
\hline & V5 Blockchain & V5 Blockchain is used in HE for a massive audience (Blockchain) \\
\hline & V5 Videoconferences & V5 Blockchain is used in HE for a massive audience (Videoconferences) \\
\hline
\end{tabular}


For the needs of the research and following the research model, a questionnaire was developed. The first group of questions consisted of socio-demographic questions. The second group of questions consisted of questions following the variables from the model (Table 1, Figure 4). A five-point Likert scale was used for this group of questions. Then, variables formulated as questions and options were given to respondents followed with a scale: disagree, partially disagree, neither disagree nor agree, partially agree, and agree.

The survey questions are as follows:

- Q1: Do you think these items promote suitable motivation for HE learning?

- Q2: Do you think these items promote suitable collaborative work for learning?

- Q3: Do you consider these items to promote suitable engagement for learning?

- Q4: Do you consider these items to promote suitable Learning Performance?

- Q5: Blockchain is used in HE for a massive audience. Please, evaluate the importance of new methods and technologies in teaching and evaluation.

Due to the rationality of the record, not all variables were analysed for this paper but only those that fit into the research model. Others are not mentioned.

\subsubsection{Data and Variables}

The data were collected from 150 students from 3 universities in Serbia, Romania, and Portugal, representing exploratory research. Thus, the results obtained cannot be extrapolated to the entire statistical population but represent preliminary and essential research for exhaustive new research on a more representative sample.

We start our analysis from the assumption that V1 influences V2 that influences V3 and V5. In addition, V3 influences V4, as presented in Table 1 and Figure 4.

\subsubsection{Research Process}

Based on the literature review, the authors designed a survey that considered V1, V2, V3, V4, and V5 variables defined above. In addition, they also considered tools such as MOOCs, AR, VR, gamification, and Videoconferences, analysed from student perspectives. Our analysis starts from the following assumptions:

Hypothesis 1 (H1). Student Motivation (V1) has a powerful and positive influence on Student Collaborative Work (V2);

Hypothesis 2 (H2). Student Collaborative Work (V2) is associated with a higher degree of student engagement in the educational process (V3);

Hypothesis 3 (H3). Student Collaborative Work is bootstrapped by the use of blockchain in HE for a massive audience (V5);

Hypothesis 4 (H4). The higher the student engagement (V3), the higher the student learning performances (V4). Student engagement bootstrapped the learning performances in HE.

Different analytical tools and applications were used to code the data and extract knowledge (Tables 2 and 3, Figures 3-5), including the correlation matrix, composite reliability, Cronbach's alpha, and bootstrapping. The variables were mined with SmartPLS3 [45-59]. After correlating data and variables and verifying the model's reliability, we designed three regression models assuming this hypothesis was not rejected. 
Table 2. Validation process of reflexive constructs.

\begin{tabular}{ccccc}
\hline $\begin{array}{c}\text { Reflexive } \\
\text { Construct }\end{array}$ & $\begin{array}{c}\text { Composite } \\
\text { Reliability }\end{array}$ & $\begin{array}{c}\text { Alpha } \\
\text { Conbrach }\end{array}$ & AVE & $\sqrt{ }$ AVE \\
\hline Criteria & $\mathbf{( > 0 . 7 )}$ & $\mathbf{( > 0 . 7 )}$ & $\mathbf{( > 0 . 5 )}$ & $\mathbf{( > 0 . 5 )}$ \\
\hline V1 & 0.873 & 0.871 & 0.582 & 0.762 \\
\hline V2 & 0.888 & 0.888 & 0.666 & 0.816 \\
\hline V3 & 0.891 & 0.890 & 0.581 & 0.762 \\
\hline V4 & 0.930 & 0.929 & 0.625 & 0.790 \\
\hline V5 & 0.932 & 0.934 & 0.700 & 0.836 \\
\hline
\end{tabular}

Table 3. Bootstrapping results (source: SmartPLS output).

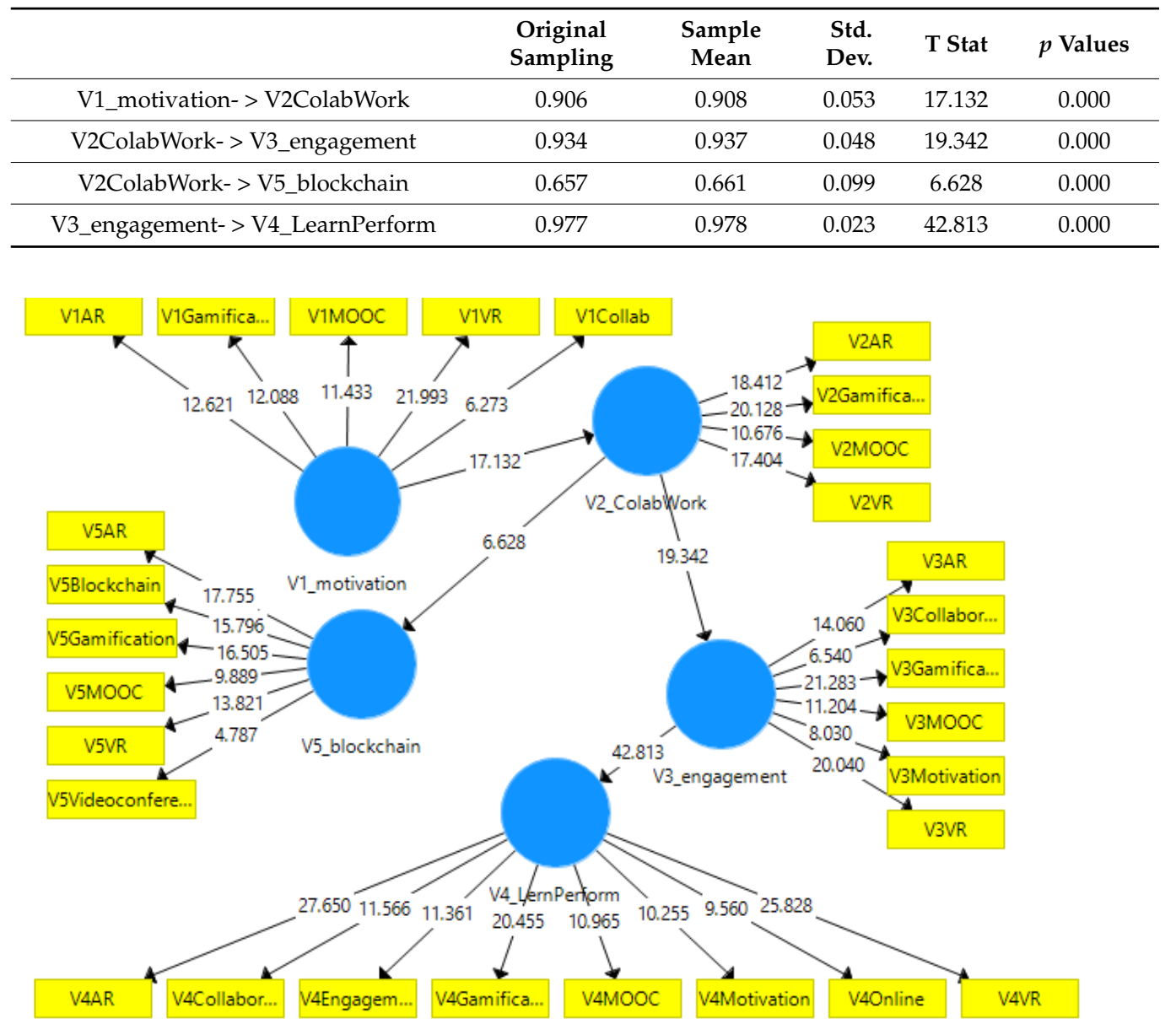

Figure 5. Bootstrapping procedure.

Furthermore, in statistical considerations, aiming to evaluate indicators, this research presents the Composite Reliability Analysis, Cronbach's Alpha Coefficients, and the Bootstrapping (Variance Inflation Factor). All these analyses aimed to present a new model.

\subsubsection{Composite Reliability}

Composite reliability is a conservative to validate if there is an overall factor of the indices and, consequently, a theoretical dimension to the construct [60]. The composite reliability can be verified through the beta coefficient [61] of internal consistency, which should be higher than 0.7 and reliability alpha [62], which should be higher than 0.8 . Values above 0.7 are already indicative of a reliable reflective measurement [63]. Figure 4 presents the composite reliability analysis. The composite reliability shows an influential model 
because all the values of the AI factors (subindices) are very high (greater than 0.7). Figure 4 presents the Composite Reliability Model.

\subsubsection{Cronbach Alpha Coefficients}

The Cronbach's coefficient (V1-0.873, V2-0.888, V3-0.891, V4-0.930, V5-0.932) demonstrates that our analysis is safe and consistent because the sub-indicators of the variables mentioned above (Table 2) correlate between themselves and with the additive result of all sub-indicators. This criterion is more significant than 0.7 for all variables and their sub-indicators. Some authors accept the 0.6 value as valid, too.

\subsubsection{Average Variance Extracted}

There are two criteria for analysing the discriminant validity of reflective measures: the Fornell-Larcker criterion and the cross-loading of the indicators [46,47]. According to the Fornell-Larcker criterion, discriminant validity is obtained when the square root of the average variance extracted (AVE) of each construct is greater than the correlation with all other indicators $[57,59]$. Table 2 presents the average variance extracted (AVE).

The correlation between the indicators can also assess the reflective measures of the constructs. The empirical tests suggested by [61] include the following: (i) internal consistency, (ii) reliability, (iii) factor average variance extracted (AVE), and (iv) factor loadings. Table 2 shows these values.

\subsubsection{Bootstrapping (Variance Inflation Factor)}

The bootstrapping procedure to identify the Variance Inflation Factor (VIF) of each construct was performed with 5000 samples and a reliability of $95 \%$ with the help of SPSS software, as suggested by [59]. The results are summarised in Table 3.

The bootstrapping procedure is summarised in Figure 5.

Considering the significance of $5 \%$ for the two-tailed test in bootstrapping, $t$-values below 1.96 are considered critical $[45,57]$. In this case, all values were considered significant. The results are summarised in Table 4 .

The existing sensitivity to sample size can be validated by the value of the factorial inflationary variance, which ensures the variance stability when it is less than five [64]. As we can verify in Figures 3-5, all hypotheses were accepted. In other words, Student Motivation (V1) has a powerful and positive influence on Student Collaborative Work (2), Student Collaborative Work (V2) is associated with a higher degree of student engagement in the educational process (V3), Student Collaborative Work is bootstrapped by the use of blockchain in HE for a massive audience (V5), and the higher the student engagement (V3), the higher the student learning performances (V4). Therefore, student engagement bootstrapped the learning performances in HE. Based on the data analysis, this research design consistent regression models according to Table 5. 
Table 4. Variables and respective indicators.

\begin{tabular}{|c|c|c|}
\hline Variable Name & Code of Indicator & Bootstrapping $(*)$ \\
\hline \multirow{5}{*}{$\begin{array}{c}\text { Student } \\
\text { Motivation }\end{array}$} & V1Collaborative & $6.273 *$ \\
\hline & V1MOOCs & 11.433 * \\
\hline & V1AR & $12.621 *$ \\
\hline & V1VR & $21.993 *$ \\
\hline & V1Gamification & $12.088^{*}$ \\
\hline \multirow{4}{*}{$\begin{array}{c}\text { Student } \\
\text { Collaborative } \\
\text { Work }\end{array}$} & V2MOOCs & $10.676^{*}$ \\
\hline & V2AR & $18.412 *$ \\
\hline & V2VR & 17.404 * \\
\hline & V2Gamification & $20.128^{*}$ \\
\hline \multirow{6}{*}{$\begin{array}{c}\text { Student } \\
\text { Engagement }\end{array}$} & V3 Collaborative_engagement & $6.540 *$ \\
\hline & V3 MOOCs & $11.204 *$ \\
\hline & V3 Motivation & $8.030 *$ \\
\hline & V3 AR & 14.060 * \\
\hline & V3 VR & $20.040 *$ \\
\hline & V3 Gamification & $21.283^{*}$ \\
\hline \multirow{8}{*}{$\begin{array}{c}\text { Student } \\
\text { Learning } \\
\text { Performance }\end{array}$} & V4 Collaborative & $11.566^{*}$ \\
\hline & V4 Motivation & $10.255^{*}$ \\
\hline & V4 Engagement & 11.361 * \\
\hline & V4 MOOCs & 10.965 * \\
\hline & V4 AR & $27.650 *$ \\
\hline & $\mathrm{V} 4 \mathrm{VR}$ & $25.828 *$ \\
\hline & V4 Gamification & $20.455 *$ \\
\hline & V4 Online class & $9.560 *$ \\
\hline \multirow{6}{*}{ Blockchain } & V5 MOOCs & $9.889 *$ \\
\hline & V5 AR & 17.755 * \\
\hline & V5 VR & $13.821 *$ \\
\hline & V5 Gamification & $16.505 *$ \\
\hline & V5 Blockchain & $15.796^{*}$ \\
\hline & V5 Videoconferences & $4.787 *$ \\
\hline
\end{tabular}

* $>1.96$, Sig of 0.05 .

Table 5. Variables and regression coefficients (source: SmartPLS output).

\begin{tabular}{|c|c|c|c|c|c|c|c|}
\hline Intercepts & & Standardized & V1_Motivation & V2_ColabWork & V3_Engagement & V4_LernPerform & V5_Blockchain \\
\hline V1_motivation & Constant & V1_motivation & & 0.803 & & & \\
\hline V2_ColabWork & 0.378 & V2_ColabWork & & & 0.837 & & 0.602 \\
\hline V3_engagement & 1.124 & V3_engagement & & & & 0.895 & \\
\hline V4_LernPerform & 0.464 & V4_LernPerform & & & & & \\
\hline V5_blockchain & 1.445 & V5_blockchain & & & & & \\
\hline
\end{tabular}

According to the results, the regression model is based on the following:

$\mathrm{V} 1=0.378+0.803 \times \mathrm{V} 2$;

$\mathrm{V} 2=1.1124+0.837 \times \mathrm{V} 3+0.602 \times \mathrm{V} 5$;

$\mathrm{V} 3=0.464+0.895 \times \mathrm{V} 4$.

The regression models are presented in Table 5 . 


\section{Discussion}

Investigating the impact of motivation on collaborative work in higher education institutions, this study examines the potential of blockchain in those institutions (HEIs). Based on the chosen methodology in his chapter, we will present the outcomes of our research based on observation, document analysis or survey results. Decentralisation, security, and integrity can all be provided by Blockchain, as well as anonymity and encryption. Furthermore, it can be seen as a consensus mechanism that rewards students, professors, and universities the same way an intelligent contract does.

Using this technology, universities have been able to raise the quality of their programs. It also gives those with less knowledge the opportunity to interact with more knowledgeable colleagues and mentors. Finally, the goal of this research is to improve the current understanding of blockchain applications.

This study's methodology includes document analysis, a literature review, content analysis (of blockchain platforms), a case study, and a survey of respondents. In addition, Cronbach's Alpha Coefficients and Bootstrapping are statistical considerations that aim to evaluate the indicators in this study (Variance Inflation Factor). Ultimately, the goal of all of this research was to present a well-thought-out research model. The data used in this exploratory study came from 150 students at 3 universities in Serbia, Romania, and Portugal.

The composite reliability shows a significant model because all of the AI factors' (subindices') values are incredibly high. As a result, a reliable analysis will have a high Cronbach's Alpha Coefficient, which indicates that the sub-indicators of each of the variables are correlated both within themselves and with the total of all their results.

Student motivation has a significant and positive impact on the quality of student collaborative work, as demonstrated by blockchain in Higher Education. Work completed by students in groups has been shown to increase student involvement in the educational process, and more involvement means better learning outcomes for the students involved. Student involvement improved learning outcomes in higher education as a result. Using blockchain-based tools and motivation, teamwork, and student involvement was critical in improving student learning outcomes. Research shows that collaborative work, motivation, engagement, MOOCs, augmented and virtual reality (AR), game-based learning, and online classes are all linked to student learning outcomes in quantitative ways.

Using blockchain, the advantage is double for students: On the one hand, a very accurate record is stored in the data source and increases the students' interest to interact with the e-learning platform; on the other hand, the HE Cloud can be stored in many blockchains for different activities [10,39].

According to this research, all variables such as Student Motivation, Student Collaborative Work, Student Engagement, Student Learning Performance and blockchain and their indicators were considered significant. Moreover, the respective relationships were accepted.

Sustainable education in the millennial era must be founded on three pillars: equity, inclusion, and personal development. This requires life-long learning approaches that incorporate digital, transversal, and practical skills (i.e., critical thinking, communication, collaboration, information literacy, analytical skills, metacognitive and reflective skills, and other research skills) $[2,3]$.

This research found that collaborative work, motivation, engagement, MOOCs, AR, $\mathrm{VR}$, gamification, and online classes were associated with learning performance. In other words, student performance can be improved through these factors. In addition, decentralising Online Learning will ensure real-time online interaction between teachers and students, and the student may have the opportunity to choose between courses from curricula.

In addition, using MOOCs, AR, VR, gamification, blockchain, and videoconferences, it is possible to implement improvements in the structure and duration of content and add learning tools. 
Furthermore, the importance of document validation must also be associated, accelerating the process and reducing costs and paperwork. Finally, blockchain is a fully inclusive process, which allows the integration of the most diverse cultures and people and the most varied learning levels. In this way, one can connect blockchain to the concept of sustainability, especially when learning in higher education institutions can be favoured by new technologies.

Blockchain will offer learning alternatives in higher education institutions through this technology. As we saw in the Technical University of Madrid (Spain), Universidade Aberta (Portugal), Open University EADTU (Netherlands), Universidad de Oviedo (Spain), and Universidade de Zaragoza (Spain), it can be promoted sustainability in the long term. In HEIs, platforms such as Tutellus, SGE, and Edgecoin will enhance the distance learning management process, student collaboration and interaction, student creativity, and higher motivation to obtain transferable skills and international recognition of thought badges. Furthermore, because of its credibility, traceability, and security, blockchain will be increasingly used in all areas: recordkeeping (for students, professors, educational institutions, and file storage), the creation of a new market for digital assets (students' fees, rewards, digital Badges, publishing fees), the creation of a disruptive business model, decentralising online learning, and the creation of better learning platforms. Soon, physical distance will matter relatively little for knowledge sharing and networking, diminishing the importance of spaces, meaning blockchain facilities will be a sustainable solution for HE.

To provide the best education, this research has presented a blockchain that focuses on including HEIs, that can decentralise and provide security and integrity, and that can offer anonymity and encryption, promoting increased transaction rates. In addition, it can be seen as a consensus mechanism, rewarding students, teachers, and universities as a smart contract. Moreover, building an educational infrastructure to support learning from this technology is a must in today's times. Finally, technologies such as MOOCs allow less-informed people to interact with more knowledgeable peers and mentors.

In describing a broad range of ideas, the paper guides the educational sphere. DLT offers many advantages, and it would be beneficial for badgification and the manuscript review process. This is because DLT helps address several problems that come with traditional methods. Online learning has given students more choice, and DLT can assist in tracking, storing, and distributing learning records. Though a well-known company is needed to start a DLT protocol, it should be noted that large corporations are required. In order to maintain the recordkeeping autonomy of the general public, this defeats the purpose of DLT development. This research gap is representative of future research priorities.

Recent research about the opportunities and challenges of artificial intelligence and machine learning [65] concluded that a personalised learning environment is especially accessible to college students these days. Both problems, which involve computers, can be handled by AI. Individualised learning experiences powered by AI, which data have enhanced, will be available to students. Two professors can discover new methods in which students learn while also offering suggestions to assist students in personalising their teaching methods to fit their learning requirements. With new approaches, colleges, universities, other educational institutions, and EdTech companies will benefit greatly from these technologies [65].

Regarding the challenges that some HEIs would need to overcome to adopt a blockchain model, we can see a resemblance to implementing artificial intelligence and machine learning. The challenges for adopting AI as defined by Mc Kinsey are as follows: the lack of a clear strategy, lack of talent with an appropriate set of skills for AI work, limitations in the functionality of end-to-end AI solutions, lack of responsibility of and commitment to AI by leaders, lack of technological infrastructure to support AI, lack of available (i.e., collected) data, uncertainty or low expectations from return on AI investment, insufficient resources for AI, limited data usefulness, personal judgment cancels AI-based decision making, limited relevance of AI insights, and lack of changes in frontline processes after the adoption of AI [66]. 


\section{Conclusions}

Our research shows that the higher the student motivation, raised mainly by new technology and teaching methodologies, the higher the student collaborative work. The interactivity and collaboration between students and or teachers are facilitated by MOOCs platforms, blockchain technology, and VR/AR dedicated applications for education. Gamification proved to be an essential tool in stimulating creativity, critical thinking, interactivity, and engagement. Videoconferences proved a beneficial solution for teaching classes at a distance in times of crisis. Collaborative activities are any activities where learners are working co-operatively in pairs or groups. Blockchain can impact the quality of collaborative work among students. It improves the communication among them, the quality of the records obtained, and how they are kept and distributed. Student collaborative work is associated with a higher degree of student engagement in the educational process. It is bootstrapped by blockchain in HEIs, having a massive audience around the students as a result. These facilities raise the student engagement rate with positive consequences and increase student learning performances. Student engagement bootstrapped the learning performances in HEI. Universities should adopt these technologies and develop new training and teaching methodologies following millennial expectations and the technological revolution (modern mobile technologies, interaction with AI, ubiquitous computing and technology, real-time communication with the students, and continuous interactions between universities and companies). The graduates of this system will be very prepared to embrace the challenges of the market in a sustainable economy.

The trainers for the university will have as their primary objective to provide sustainable education and face the current economic, environmental, and medical challenges. The blockchain marketing system of MOOCs rewards both teachers and students for their activities with discount vouchers that might be transformed into the virtual currency. This system will ensure high engagement in the courses and the resources for a sustainable platform.

We may observe that even the vanguardist HEIs which implemented Blockchain did not cover all the facilities yet. This acts for obvious reasons as a limitation for the moment, given digital literacy, the newness of blockchain technology, and its complex character. One big problem that seems not to be solved in the digital environment is students' socio-emotional and cognitive development. Future research can bring a certain emotional balance in our societies, a kind of reward, such as those who support blockchain technologies, including education.

Blockchain technologies can be adopted in HEIs to improve teaching methods and create better learning platforms and recordkeeping and improve student motivation, collaborative work, engagement, and learning performance and like.

This research adds to the body of knowledge on blockchain implementation in higher education and evaluates the significance of the technology for student learning outcomes. For example, MOOCs, AR, VR, gamification, and videoconferences can be implemented in HE to reach a much larger audience. Furthermore, it affects how well students learn. As a result, student learning performance is dependent on a combination of factors, including collaborative work, student motivation, involvement in online courses and blockchain tools such as MOOCs, AR, VR, and gamification. As a result of bringing people together and encouraging knowledge sharing, blockchain can help improve learning outcomes. As formulated after the literature review, closing the research gap is how to overcome the challenges of blockchain implementation in HEI.

There are certain limitations to every study, and this one is no different. Due to social desirability, generalizability, the imprecision of measures, and unasked questions, this study has limitations. A focus on concrete platforms and projects for HEIs in low- and middle-income countries and promoting best practices is needed in future research to help HEIs overcome the difficulties they face.

In light of the study's limitations, we will keep looking into new ways to put blockchain technology to use. In addition, not all facilities were covered by the pioneering HEIs that 
embraced blockchain technology. This is a shortcoming for the time being, given the low level of digital literacy and the complexity of blockchain technology.

Furthermore, there is no digital solution for the socio-emotional and cognitive development of students. As a result, we continue to seek solutions, primarily in the form of psychological assistance. The psychologist's answers are still awaited.

Author Contributions: Conceptualisation, R.B.-M.-T,. (Radu Bucea-Manea-T,oniş), R.B.-M.-T, (Rocsana Bucea-Manea-T,oniş) and C.G.; methodology, R.B.-M.-T. (Rocsana Bucea-Manea-Țoniş), V.K., M.P.I. and O.M.D.M.; software, R.B.-M.-T, (Radu Bucea-Manea-Toniş); validation, R.B.-M.-T. (Radu Bucea-Manea-T,oniş), C.G., V.K. and M.P.I.; formal analysis, R.B.-M.-T. (Radu Bucea-Manea-Țoniş); investigation, R.B.-M.-T. (Rocsana Bucea-Manea-Toniş), C.G., V.-E.S., V.K. and M.P.I.; resources, R.B.-M.-T. (Rocsana Bucea-Manea-T,oniş) and V.-E.S.; data curation, R.B.-M.-T. (Radu Bucea-ManeaT,oniş) and O.M.D.M.; writing—original draft preparation, R.B.-M.-T,. (Rocsana Bucea-Manea-Toniş), V.-E.S.; C.G., V.K. and M.P.I.; writing—review and editing, R.B.-M.-T,. (Radu Bucea-Manea-Toniş), O.M.D.M., V.K. and C.G.; visualisation, M.P.I. and O.M.D.M.; supervision, R.B.-M.-T. (Rocsana Bucea-Manea-Toniş) and O.M.D.M.; project administration, C.G. and V.K. All authors have read and agreed to the published version of the manuscript.

Funding: This research received no external funding.

Informed Consent Statement: Informed consent was obtained from all subjects involved in the study.

Conflicts of Interest: The authors declare no conflict of interest.

\section{References}

1. Antó, J.M.; Martí, J.L.; Casals, J.; Bou-Habib, P.; Casal, P.; Fleurbaey, M.; Frumkin, H.; Jiménez-Morales, M.; Jordana, J.; Lancelotti, C.; et al. The Planetary Wellbeing Initiative: Pursuing the Sustainable Development Goals in Higher Education. Sustainability 2021, 13, 3372. [CrossRef]

2. Gräther, W.; Kolvenbach, S.; Ruland, R.; Schütte, J.; Torres, C.; Wendland, F. Blockchain for Education: Lifelong Learning Passport. In Proceedings of the 1st ERCIM Blockchain Workshop 2018, Amsterdam, The Netherlands, 8-9 May 2018; Prinz, W., Hoschka, P., Eds.; Reports of the European Society for Socially Embedded Technologies. EUSSET: Troyes, France, 2018; Volume 2, p. 10. [CrossRef]

3. Yakovenko, I.; Kulumbetova, L.; Subbotina, I.; Zhanibekova, G.; Bizhanova, K. The blockchain technology as a catalyst for digital transformation of education. Int. J. Mech. Eng. Technol. (IJMET) 2019, 10, 886-897.

4. United Nation. Policy Brief: Education during COVID-19 and Beyond. August 2020. Available online: https://www.un.org/ development/desa/dspd/wp-content/uploads/sites/22/2020/08/sg_policy_brief_covid-19_and_education_august_2020 .pdf (accessed on 23 September 2021).

5. Seshaiyer, P. eLearning Workshop Series: Leadership Program for Education Authorities (LPEA)—Innovations in Curriculum, Teaching and Learning. Available online: https://www.youtube.com/c/GlobalDevelopmentInstitute/videos (accessed on 23 September 2021).

6. Alfonso Viguria, U.; Casamitjana, N. Early Interventions and Impact of COVID-19 in Spain. Int. J. Environ. Res. Public Health 2021, 18, 4026. [CrossRef] [PubMed]

7. Toubes, D.R.; Araújo Vila, N.; Fraiz Brea, J.A. Changes in Consumption Patterns and Tourist Promotion after the COVID-19 Pandemic. J. Theor. Appl. Electron. Commer. Res. 2021, 16, 1332-1352. [CrossRef]

8. Royo-Vela, M.; Velasquez Serrano, M. Value Co-Creation Process and Measurement in 4.0 SMEs: An Exploratory Research in a B2B Marketing Innovation Context. Adm. Sci. 2021, 11, 20. [CrossRef]

9. Fenichel, M.; Schweingruber, H.A. Surrounded by Science: Learning Science in Informal Environments; Board on Science Education, Center for Education, Division of Behavioral and Social Sciences and Education; The National Academic Press: Washington, DC, USA, 2010.

10. Abad-Segura, E.; González-Zamar, M.D.; Infante-Moro, J.C.; Ruipérez-García, G. Sustainable Management of Digital Transformation in Higher Education: Global Research Trends. Sustainability 2020, 12, 2107. [CrossRef]

11. Seshaiyer, P.; Hilker-Balkissoon, K. Integrating Career, Global and Experiential Learning: A STEAM Case Study. In Proceedings of the Innovations in Teaching \& Learning Conference Proceedings, Fairfax, VA, USA, 27 September 2019. [CrossRef]

12. Suh, J.M.; Seshaiyer, P. Promoting Ambitious Teaching and Learning through Implementing Mathematical Modeling in a PBL Environment: A Case Study. In The Wiley Handbook of Problem-Based Learning; Moallem, M., Hung, W., Dabbagh, N., Eds.; John Wiley \& Sons, Inc.: Hoboken, NJ, USA, 2019. [CrossRef]

13. Rodrigues, J.D.S. Blockchain: Um Novo Modelo Social e Financeiro. Ph.D. Thesis, Universidade Fernando Pessoa, Porto, Portuguese, 26 November 2019. Available online: http:/ / hdl.handle.net/10284/8354 (accessed on 22 July 2021).

14. Suh, J.; Matson, K.; Seshaiyer, P.; Jamieson, S.; Tate, H. Mathematical Modeling as a Catalyst for Equitable Mathematics Instruction: Preparing Teachers and Young Learners with 21st Century Skills. Mathematics 2021, 9, 162. [CrossRef] 
15. Banerjee, R.; Seshaiyer, P. Challenges in School Mathematics Curriculum Reform in India: Transforming Teacher Practices Through Pedagogical Innovations. In School Mathematics Curricula; Mathematics Education-An Asian Perspective; Vistro-Yu, C., Toh, T., Eds.; Springer: Singapore, 2019. [CrossRef]

16. Antonaci, A.; Klemke, R.; Lataster, J.; Kreijns, K.; Specht, M. Gamification of MOOCs adopting social presence and sense of community to increase user's engagement: An experimental study. In European Conference on Technology Enhanced Learning, Proceedings of the 14th European Conference on Technology Enhanced Learning, EC-TEL 2019, Delft, The Netherlands, 16-19 September 2019; Springer: Cham, Switzerland, 2019; pp. 172-186.

17. Bucea-Manea-Tonis, R.; Gurgu, E.; Martins, O.M.D.; Simion, V.E. An Overview of How VR/AR Applications Assist Specialists in Developing Better Consumer Behavior and Can Revolutionise Our Life. In Consumer Happiness: Multiple Perspectives; Springer: Berlin/Heidelberg, Germany, 2021; pp. 231-253. Available online: https://www.springer.com/gp/book/9789813363731\# aboutBook (accessed on 22 July 2021).

18. Antonaci, A.; Klemke, R.; Stracke, C.M.; Specht, M. Identifying game elements suitable for MOOCs. In Proceedings of the European Conference on Technology Enhanced Learning, Tallinn, Estonia, 12-15 September 2017; Springer: Cham, Switzerland, 2017; pp. 355-360.

19. Bidarra, J.; Coelho, J. Once upon a tip ... : A story of MOOCs and gamification. In Proceedings of the EADTU Conference 2017: The Open and Flexible Higher Education Conference, Milton Keynes, UK, 25-27 October 2017; EADTU: Maastricht, The Netherlands, 2017.

20. Androutsos, A.; Brinia, V. Developing and Piloting a Pedagogy for Teaching Innovation, Collaboration, and Co-Creation in Secondary Education Based on Design Thinking, Digital Transformation, and Entrepreneurship. Educ. Sci. 2019, 9, 113. Available online: https: / / www.mdpi.com/2227-7102/9/2/113 (accessed on 22 July 2021). [CrossRef]

21. Oyelere, S.S.; Tomczyk, L.; Bouali, N.; Agbo, F.J. Blockchain technology and gamification-conditions and opportunities for education. In Adult Education 2018-Transformation in the Era of Digitization and Artificial Intelligence; Dspace: Brno, Czech Republic, 2019; pp. 85-96.

22. Guustaaf, E.; Rahardja, U.; Aini, Q.; Maharani, H.; Santoso, N. Blockchain-based Education Project. Aptisi Trans. Manag. (ATM) 2021, 5, 46-61. [CrossRef]

23. Yumna, H.; Khan, M.; Ikram, M.; Ilyas, S. Use of Blockchain in Education: A Systematic Literature Review. In Asian Conference on Intelligent Information and Database Systems; Springer: Cham, Switzerland, 2019; pp. 191-202.

24. Adiyanto, A.R. Febrianto Authentication of Transaction Process In E-marketplace Based on Blockchain technology. Aptisi Trans. Technopreneurship 2020, 2, 68-74. [CrossRef]

25. Chen, G.; Xu, B.; Lu, M.; Chen, N.S. Exploring blockchain technology and its potential applications for education. Smart Learn. Environ. 2018, 5, 1-10. [CrossRef]

26. Harahap, E.P.; Aini, Q.; Anam, R.K. Pemanfaatan Teknologi Blockchain Pada Platform Crowdfunding. Technomedia J. 2020, 4, 199-210. [CrossRef]

27. Mohanty, D. Ethereum Use Cases. In Ethereum for Architects and Developers; Springer; Apress: Berkeley, CA, USA, 2018; pp. 203-243. [CrossRef]

28. Imoize, A.L.; Adedeji, O.; Tandiya, N.; Shetty, S. 6G Enabled Smart Infrastructure for Sustainable Society: Opportunities, Challenges, and Research Roadmap. Sensors 2021, 21, 1709. [CrossRef] [PubMed]

29. Alammary, A.; Alhazmi, S.; Almasri, M.; Gillani, S. Blockchain-based applications in education: A systematic review. Appl. Sci. 2019, 9, 2400. [CrossRef]

30. Sun, H.; Wang, X.; Wang, X. Application of blockchain technology in online education. Int. J. Emerg. Technol. Learn. (IJET) 2018, 13, 252-259. [CrossRef]

31. Bhaskar, P.; Tiwari, C.K.; Joshi, A. Blockchain in education management: Present and future applications. Interact. Technol. Smart Educ. 2021, 18, 1-17. [CrossRef]

32. UE: Digital Education Action Plan (2021-2027). Available online: https:/ / ec.europa.eu/education/education-in-the-eu/digitaleducation-action-plan_en (accessed on 22 July 2021).

33. Dybach, I. Institutional aspects of educational quality management in higher educational establishments. Econ. Dev. 2019, 18, 33-43. [CrossRef]

34. Jirgensons, M.; Kapenieks, J. Blockchain and the Future of Digital Learning Credential Assessment and Management. J. Teach. Educ. Sustain. 2018, 20, 145-156. [CrossRef]

35. Surendran, K.; Benny, L.; Mahesh, A.S. Student academic management system using blockchain technology. J. Adv. Res. Dyn. Control Syst. 2020, 12, 1410-1415. [CrossRef]

36. Ito, K.; O'Dair, M. A Critical Examination of the Application of Blockchain Technology to Intellectual Property Management. In Business Transformation through Blockchain; Treiblmaier, H., Beck, R., Eds.; Palgrave Macmillan: Cham, Switzerland, 2019; pp. 317-335. [CrossRef]

37. Han, M.; Li, Z.; He, J.S.; Wu, D.; Xie, Y.; Baba, A. A Novel Blockchain-based Education, Records Verification Solution. In Proceedings of the 19th Annual Conference on Information Technology Education (SIGITE'18), Fort Lauderdale, FL, USA, 3-6 October 2018; ACM: New York, NY, USA, 2018; pp. 178-183. [CrossRef]

38. Mahlow, C.; Hediger, A. Digital Transformation in Higher Education—Buzzword or Opportunity? ELearn 2019, 5, 13. [CrossRef] 
39. Mikroyannidis, A.; Domingue, J.; Bachler, M.; Quick, K. Smart Blockchain Badges for Data Science Education. In Proceedings of the 2018 IEEE Frontiers in Education Conference (FIE), San Jose, CA, USA, 3-6 October 2018; pp. 1-5. [CrossRef]

40. Kolvenbach, S.; Ruland, R.; Gräther, W.; Prinz, W. Blockchain 4 Education. In Proceedings of the 16th European Conference on Computer-Supported Cooperative Work, Demos and Posters, Reports of the European Society for Socially Embedded Technologies, Nancy, France, $4-8$ June 2018. [CrossRef]

41. Borrás-Gené, O.; Martínez-Núñez, M.; Fidalgo-Blanco, Á. New Challenges for the Motivation and Learning in Engineering Education Using Gamification in MOOC. Int. J. Eng. Educ. 2016, 32, 501-512. Available online: https://repositorio.grial.eu/ bitstream/grial/560/1/19_ijee3155ns.pdf (accessed on 23 September 2021).

42. Yuan, M.; Li, X.; Li, X.; Tan, H.; Xu, J. Trust Hardware Based Secured Privacy Preserving Computation System for ThreeDimensional Data. Electronics 2021, 10, 1546. [CrossRef]

43. Ullah, N.; Mugahed Al-Rahmi, W.; Alzahrani, A.I.; Alfarraj, O.; Alblehai, F.M. Blockchain Technology Adoption in Smart Learning Environments. Sustainability 2021, 13, 1801. [CrossRef]

44. Ramirez-Asis, E.; Maguina, M.E.; Infantes, S.E.; Naranjo-Toro, M. Emotional intelligence, competencies and performance of the university professor: Using the SEM-PLS partial least squares technique. Rev. Electron. Interuniv. Form. Profr. 2020, 23, 99-114. [CrossRef]

45. Hair, J.F.; Risher, J.J.; Sarstedt, M.; Ringle, C.M. When to use and how to report the results of PLS-SEM. Eur. Bus. Rev. 2019, 31, 2-24. [CrossRef]

46. Allen, J.; Eboli, L.; Mazzulla, G.; Dios Ortúzar, J. Effect of critical incidents on public transport satisfaction and loyalty: An Ordinal Probit SEM-MIMIC approach. Transportation 2020, 47, 827-863. [CrossRef]

47. Papantoniou, P. Structural equation model analysis for the evaluation of overall driving performance: A driving simulator study focusing on driver distraction. Traffic Inj. Prev. 2018, 19, 317-325. [CrossRef]

48. Abdulrab, M.; Al-Mamary, Y.H.S.; Alwaheeb, M.A.; Alshammari, N.G.M.; Balhareth, H.; Al-Shammari, S.A. Mediating role of strategic orientations in the relationship between entrepreneurial orientation and performance of Saudi SMEs. Braz. J. Oper. Prod. Manag. 2021, 18, 1-15. [CrossRef]

49. Aboelmaged, M. The drivers of sustainable manufacturing practices in Egyptian SMEs and their impact on competitive capabilities: A PLS-SEM model. J. Clean. Prod. 2018, 175, 207-221. [CrossRef]

50. Cho, G.; Choi, J.Y. An empirical comparison of generalised structured component analysis and partial least squares path modelling under variance-based structural equation models. Behaviormetrika 2020, 47, 243-272. [CrossRef]

51. Ghasemy, M.; Teeroovengadum, V.; Becker, J.-M.; Ringle, C.M. This fast car can move faster: A review of PLS-SEM application in higher education research. High. Educ. 2020, 80, 1121-1152. [CrossRef]

52. Chin, W.; Cheah, J.H.; Liu, Y.; Ting, H.; Lim, X.J.; Cham, T.H. Demystifying the role of causal-predictive modelling using partial least squares structural equation modelling in information systems research. Ind. Manag. Data Syst. 2020, 120, $2161-2209$. [CrossRef]

53. Danks, N.P.; Sharma, P.N.; Sarstedt, M. Model selection uncertainty and multimodel inference in partial least squares structural equation modelling (PLS-SEM). J. Bus. Res. 2020, 113, 13-24. [CrossRef]

54. Franke, G.; Sarstedt, M. Heuristics versus statistics in discriminant validity testing: A comparison of four procedures. Internet Res. 2019, 29, 430-447. [CrossRef]

55. George, D.; Mallery, P. IBM SPSS Statistics 25 Step by Step: A Simple Guide and Reference, 15th ed.; Routledge: New York, NY, USA, 2019.

56. Hair, J.F.; Hult, G.T.M.; Ringle, C.M.; Sarstedt, M. A Primer on Partial Least Squares Structural Equation Modelling (PLS-SEM), 3rd ed.; Sage: Thousand Oaks, CA, USA, 2021.

57. Cepeda Carrión, G.; Cegarra-Navarro, J.-G.; Cillo, V. Tips for using partial least squares structural equation modelling (PLS-SEM) in knowledge management. J. Knowl. Manag. 2019, 23, 67-89. [CrossRef]

58. Sarstedt, M.; Ringle, C.M.; Hair, J.F. Partial Least Squares Structural Equation Modeling. In Handbook of Market Research; Homburg, C., Klarmann, M., Vomberg, A.E., Eds.; Springer International Publishing AG: Berlin/Heidelberg, Germany, 2017 ; pp. 1-47.

59. Rossiter, J.R. The C-OAR-SE procedure for scale development in marketing. Int. J. Res. Mark. 2002, 19, 305-335. [CrossRef]

60. Revelle, W. Hierarchical Cluster Analysis and The Internal Structure of Tests. Multivar. Behav. Res. 1979, 14, 57-74. [CrossRef]

61. Churchill, G.A., Jr. A Paradigm for Developing Better Measures of Marketing Constructs. J. Mark. Res. 1979, 16, 64-73. [CrossRef]

62. Gudergan, S.P.; Ringle, C.M.; Wende, S.; Will, A. Confirmatory Tetrad Analysis in PLS Path Modeling. J. Bus. Res. 2008, 61, 1238-1249. [CrossRef]

63. Coltman, T.; Devinney, T.M.; Midgley, D.F.; Venaik, S. Formative versus reflective measurement models: Two applications of formative measurement. J. Bus. Res. 2008, 61, 1250-1262. [CrossRef]

64. Diamantopoulos, A.; Winklhofer, H. Index Construction with Formative Indicators: An Alternative to Scale Development. J. Mark. Res. 2001, 38, 269-277. [CrossRef]

65. Kuleto, V.; Ilić, M.; Dumangiu, M.; Ranković, M.; Martins, O.M.D.; Păun, D.; Mihoreanu, L. Exploring Opportunities and Challenges of Artificial Intelligence and Machine Learning in Higher Education Institutions. Sustainability 2021, 13, 10424. [CrossRef]

66. Kinsley, M. AI Adoption Advances, but Foundational Barriers Remain. 13 November $2018 . \quad$ Available online: https://www.mckinsey.com/featured-insights/artificial-intelligence/ai-adoption-advances-but-foundational-barriersremain (accessed on 16 October 2021). 